\title{
How Individual Investors React to Negative Events in the FinTech Era? Evidence from China's Peer-to-Peer Lending Market
}

\author{
Xueru Chen ${ }^{1}$, Xiaoji Hu² and Shenglin Ben ${ }^{3}$ \\ ${ }^{1}$ Zhejiang University, School of Management, Hangzhou, China, chenxueru@zju.edu.cn \\ ${ }^{2}$ Renming University of China, School of Finance, Beijing, China, huxiaojiy3@ruc.edu.cn \\ ${ }^{3}$ Zhejiang University, School of Management \& International Business School, Hangzhou, China, \\ benshenglin@zju.edu.cn
}

Received 11 August 2019; received in revised form 6 February 2020; accepted 15 February 2020

\begin{abstract}
Inexperienced individual investors are the main players in the emerging FinTech industry, and also suffer from frequent negative events in the markets. With 3,110 negative events and 467,594 transaction data of China's peer-to-peer lending market from 2015 to 2018, this paper analyzes how different types of platform negative events affect the decision-making of individual investors. We find that individual investors only have a significant negative reaction to moral hazard exposure events such as platforms absconding, with relatively ignorance of other types of negative events. The negative effect is rapid but short-lived, and shows differences among platforms of different background and attributes. By the mediation analysis, we find that public attention can be a mediator and explain the pattern of the impact that absconding events have on individual investors. Related risk prevention, regulation, investor education issues are discussed and further suggestions are also put forward for both individual investors and regulators.
\end{abstract}

Keywords: Peer-to-peer lending, Negative events, Platform absconding, Public attention, Mediation analysis 


\section{Introduction}

Recently, FinTech development has quickly removed inconveniences experienced by customers who used financial services in the past with reducing disparity and contributing to inclusive growth [53]. It has also experienced both headlining successes and serious challenges during its early development [13]. The widespread use of digital infrastructures allows cost-efficient operations [42] and lowers the threshold for public to access to financial products and services. Taking its place as a major player in the FinTech field, peer-to-peer (P2P) lending is a certain breed of financial transaction that occurs directly between individuals [33] and the practice of lending money to individuals or businesses through online services which match lenders with borrowers. Thanks to the Internet, big data and credit technology which make an efficient, convenient, secure, and low-cost online peer-to-peer lending model possible. Usually, the platforms are responsible for reviewing the borrowers' information, help borrowers publish loans requirements, collect money from individual investors and transfer it to the borrowers. The P2P investors can identify and choose which borrowers to invest from different platforms and purchase loans that meet their investment criteria.

Due to the special attributes of FinTech products and services at this stage, individual investors and consumers have become main target groups, especially in the P2P lending market. As one of the largest and most active P2P lending markets in the world, the 2016 P2P Lending Investor Survey Report from China shows that individual investors make up the majority of participants, with young people in their 20 s and 30 s becoming the main force. New investors with investment experience within 3 months accounted for $20.37 \%$, and 3-6 months accounted for $28.77 \%$ of all P2P lending investors. 58.18\% of investors are from the working class. Generally, individual investors invest in much smaller amounts than institutional investors, and are believed to be less informed and professional. In the P2P lending market, with limited and passive information submitted and disclosed by potential borrowers and the platforms [49] individual investors are more likely to be trapped in information asymmetry. It may create adverse selection and moral hazard problems that could eventually lead to a high risk of loan default [1]. [15] has concluded individual investors that (1) discover naive patterns in past price movements, (2) share popular models of value, (3) are not properly diversified, and (4) trade in suboptimal ways. However, the traditional financial market is dominated by institutional investors. In 2017, the shareholding ratio of individual investors in the US stock market was only $6 \%$, while in China, which is not a fully mature stock market, the ratio was also only $21.2 \%$. The behavior of individual investors cannot be completely isolated to study. Now, such a new FinTech market as P2P lending, which is mainly composed of individual investors, provides us an excellent opportunity and scenario for studying the behavior of individual investors. But few researches have been done so far.

In China's P2P lending market, the frequent occurrence of platform negative events has also brought great troubles and concerns to the individual investors. Just during the 42 days from June 1 to July 12, 2018, there were 108 P2P lending platforms suffered from negative problems across the country, including absconding with money, delayed payment due to difficulties in cash withdrawal and suspension of the platforms, which affected over 10 million individual investors and put more than 7 trillion assets at risk. In a short time, the emergence of a large number of related news reports also attracted great attention from the public. Some investors even went to the government office to ask for official help to defend their rights and financial security. In traditional financial markets, big negative events often lead to unexpected returns and stock market volatility [52] and participants may also lose their ability to rationally assess the implications of the event [2]. In an emerging market like P2P lending, the occurrence of platform negative events such as platform absconding, withdrawal difficulties and closure will also undoubtedly affect the behaviors of investors and the following transactions in the market. However, we know little about that. To date, there has been few systematic researches studying on the reaction of individual investors on these negative events and how it works in P2P lending and other emerging markets. We believe that such research is very urgent and necessary, because it can help us better understand the behavior of individual investors in the new financial market, so as to better promote the investor education and industry regulation.

In this paper, taking China's $\mathrm{P} 2 \mathrm{P}$ lending market as an example, we explore and analyze how individual investors react to negative events in the FinTech era and whether public attention plays a role in this process. Following the introduction, we discuss related literature on individual investors' reaction to negative events, investors research on Fintech and P2P lending, and public attention in financial research. In the third section, we propose four main hypotheses based on the literature and theories as well as observations from the market. The fourth part describes the data source and the model setting, and we comprehensively analyze the empirical results in the section 5 . Further in the section 6, we discuss the related risk prevention, regulation and investor education issues in the P2P lending market and provide suggestions for both the individual investors and regulators. Finally, we conclude the study and provide possible ideas for future research. 


\section{Literature Review}

In this section, we focus on the discussion of relevant literature including individual investors' reaction to negative events, investors research on Fintech and P2P lending, and public attention in financial research.

\subsection{Individual Investors' Reaction to Negative Events}

In traditional financial research, many scholars have studied the reaction of market-wide investors to negative events occurred in the market [4], or inside enterprises [37].

Focused on individual investors, [31] provided evidence of informed trading by individual investors around earnings announcements and found that individuals trade in both return-contrarian and news-contrarian manners after unexpected earnings announcements. [14] examined the trading behaviors of individual investors around a unique corporate event: unfaithful disclosure and found that the market had reacted negatively toward announcements on forewarnings of unfaithful disclosure by the Korean Exchange. Their findings added evidence to the information asymmetry among different types of investors prior to the news release as well as the trading behaviors by individual investors who are unsophisticatedly following the news release. Also, [26] mentioned that inconsistent with the individual trading hypothesis, the trading of individual investors failed to subsume any of the power of extreme earnings surprises to predict future abnormal returns and individuals were significant net buyers after negative extreme earnings surprises.

In recent years, although more scholars have studied the behavior of individual investors, most of them focus on daily trading and transaction [9] and there are few researches focusing on the reaction of individual investors to negative events in the financial markets, let alone the P2P lending market. In traditional financial markets such as stock and bonds markets, institutional investors are the important players and own more than $80 \%$ of the equity market cap. So, the sentiment and behavior of individual investors cannot be easily measured and analyzed through market performance.

\subsection{Investors Research on FinTech and P2P Lending}

With the innovation and rapid development of FinTech and its violent impact on the traditional financial industry, the number of FinTech research has shown an exponential increase recently. Some exploratory studies related to investor relations [17], investors' perspective of crowdfunding [39] and investor protection [34] have been done in the context of a globalized, technological and inclusive FinTech world.

Scholars have a strong research interest in the behavior and trade of investors in the online P2P lending market. [32] first discussed the question that how can inexperienced investors who operate in a pseudonymous online environment with potentially significant information asymmetries be able to obtain an attractive return on their investment and put up some simple investment rules of P2P lending investment. Following that, several researchers [21] have further discussed the information asymmetry problem between investors and borrowers in P2P lending. In 2011, [36] developed a data-driven investment decision-making framework, which exploited the investor composition of each investment and proposed an investor composition analysis model in P2P lending market. Of course, due to the special investor structure of P2P lending market, all of these studies focused on individual investors.

As an immature market, platform negative events such as absconding with investors' funds, suddenly bankrupt and cash flow rupture have frequently emerged in China's P2P industry. This kind of negative events heavily damaged the interest of investors and also spooked a large number of investors. Thus, some Chinese scholars have begun to pay attention to P2P lending platform management, regulation and investor protection issues. [23] analyzed the behavior of borrowers, government and platforms, and revealed the risks of P2P lending industry by prospect theory and evolutionary dynamic game theory. [50] in their paper examined how to persuade investors to develop initial trust in the platforms and concluded that social capital, risk management, and operating duration provided the necessary supports. They also raised that negative information would directly impact investors' confidence in P2P lending and the risk of capital chain rupture would seriously endanger the sustainable development of platforms. According to [20], (1) business closure or demise/bankruptcy of the platform, (2) difficulty in withdrawing funds at prematurity or maturity and (3) management or staff absconding with investors' funds were the most frequent negative events happened in the P2P lending industry. The occurrence of this type of negative events damaged the trust of investors and also led to the failure of most platforms. These negative events are infrequent in traditional financial markets, so investors are not fully informed and scholars also have limited understanding of their influences. Within the scope of our knowledge, how individual investors conduct and change their investment behavior in the wake of these negative events and other important issues related to this have not been further studied. 


\subsection{Public Attention in Financial Research}

In 1973, [30] first proposed an explanation of public attention by using cognitive capacity theory and further formed the definition of limited attention in behavior finance. Recently, many scholars have studied on the relationship between public attention and investors behavior, asset price, stock market activity and volatility. Typically, [44] claimed that public attention is responsible for many observed stock market anomalies and may be a major contributing factor to the excessive volatility, [7] tested and confirmed that individual investors are net buyers of the attention-grabbing stocks and [5] showed that one important channel through which more central lead initial public offering (IPO) underwriters achieve favorable IPO characteristics is by attracting greater public attention. [10] mentioned in their research that investors were more likely to overtrade once exposed to negative news, their limited and selective attention was correlated to the investors' trading behaviors.

Focusing on the measurement of public attention, scholars have designed a series of proxy variables. Tradition proxy variables includes abnormal returns [7], trading volume [22], special events [43], and media coverage [5]. A common problem of these traditional proxy variables of public attention is that they are all indirect measurements and cannot directly measure the intensity and trends of investor attention. Moreover, the change of many factors unrelated to public attention may also lead to the change of the above indicators. With the development of the Internet and the change of people's lifestyles and habits, search engine has become one of the main channels for the crowd to obtain financial information, and also provides a precise and direct measurement for the research of public attention [38]. [46] has pointed out that the search data can portray the public's interest and attention in economic activities in real time, and be used to predict the sales of houses, tourism, private consumption, as well as the unemployment rate. With Google Trends, many scholars measured the public attention and explained its role in influencing stock trading volume and price [19], the underpricing and the long-term underperformance after IPO [46] and the market index returns in financial markets. In China, similar to the Google Trends, Baidu Index is usually used as the proxy variable to measure public attention and its role in stock returns [54], market volatility [51], decisions of fund investors [55], individual investors sentiment [36] and the price, liquidity, and volatility of the index futures [28].

So far, there are very few research articles on the impact of public attention on P2P lending activities. Based on the case studies of seven representative P2P platforms, [16] found the public sentiment guiding role of media coverage on the Internet, and its impact on P2P individual investors. Empirical research on the influence of public attention on the behavior of P2P individual investors is still blank.

\section{Hypothesis}

Behavioral finance studies [8] suggested that individual investors have risk-averse and loss-averse performance in their trading. In P2P lending market, event risk could be seen as one of the most significant risks. It represents the possibility that unforeseen events would negatively affect the platforms, the participants and even the whole industry. When P2P lending negative events happened, we believe that, just like how it works in the traditional financial markets, it will also dramatically affect the optimal strategy of the investors in this new market. Platform closure, difficulty in withdrawing and absconding with money are the most frequent negative events occurred in the P2P lending industry and these negative events often led to the failure of most platforms [20]. When a large number of platform-level negative events happen together, such negative effect will rise to the industry level and have an influence on all investors in the industry. Individual investors could observe the moral hazard (absconding), liquidity risk (difficulty in withdrawing) and operational risk (closure) existing on the problem platforms and the whole industry. In order to avoid the risk of loan default or even losing all the money, they will instinctively incline to change the original investment plan or even withdraw the existing investment. And new individual investors are also temporarily lacking the incentive to enter the market, with being on the sidelines. It is reasonable to believe that when negative events of P2P platforms occur in the industry, it will affect the investment volume subsequently, and the total number of individual investors participating in $\mathrm{P} 2 \mathrm{P}$ investment will also decrease accordingly. Based on this, we propose:

\section{H1: Negative events have a negative impact on the trading volume and participation of $P 2 P$ individual investors in the market.}

In traditional financial research, many scholars found that investors' reactions to emergencies were rapid but transient. For instance, [11] resulted that the decline in the information content of earnings after restatement announcements was short-lived and the earnings response coefficient (ERC) bounced back after three quarters, and [12] supported the price pressure hypothesis, which posited that event announcement does not carry information and any shift in demand (and hence the corresponding price change and liquidity change) is temporary.

Similarly, in P2P lending market, negative events of P2P platforms have always been happening. Therefore, for individual investors who make investments in the current period, their most concern should be the recent negative events rather than the previous ones. This makes the negative impact on individual investors happen rapidly but shortlived when particular negative events occurred. Also, research on individual investors often finds that individual investors tend to be short-sighted, emotional and forgetful. When negative events occur on the platforms, individual investors will be vulnerable to external information and thus quickly reduce their investments in a short time due to risk 
aversion. However, these negative events will also be quickly forgotten by the individual investors. They will be influenced by other information and their eyes will be drawn to subsequent and recent events. According to that, we propose:

\section{H2: The negative impact of negative events on P2P individual investors is rapid but short-lived.}

Information asymmetry is also a phenomenon that cannot be ignored in the P2P lending industry [21]. It represents that individual investors are lack of information on both the borrowers and platforms and may face adverse selection and moral hazard problems which could eventually lead to a high risk of loan default. Under such circumstances, individual investors can only judge the security of the platforms through some of their attributes and disclosed information. For example, researches show that ownership of platforms [27] and reputation [41] become channels for investors to alleviate the problem of information asymmetry. And whether the platform has guarantees [40] and trusteeship [47] has also become important attributes of the platform, which could better get the trust from the investors and influence individual investors' investment decisions. Some researches showed that in the P2P lending industry, the rate discrimination was existing among platforms of different ownership, and borrowing rate had a negative correlation with rate of bad debts in private P2P lending platforms but had no correlation with that in non-private P2P lending platforms.

Most of these studies are based on the Chinese market, which is also in line with the current status and reality of the development of China's P2P lending industry. Based on this, it is reasonable to believe that investors on the platforms with high reputation, good background, guarantee and trusteeship have more confidence in the stability and security of the platforms, so they will not easily be influenced by negative events happened on other platforms and change their investment decisions. As a whole, investor on these kinds of platforms are expected to be less sensitive to negative events. Thus, the transactions on these P2P lending platforms will keep relatively stable. Thus, we propose:

\section{H3-1: Negative events have less impact on the trading volume and individual investors participation of highly reputable} platforms.

H3-2: Negative events have less impact on the trading volume and individual investors participation of the platforms with non-private background.

H3-3: Negative events have less impact on the trading volume and individual investors participation of the platforms providing guarantee.

H3-4: Negative events have less impact on the trading volume and individual investors participation of the platforms providing trusteeship.

If negative events have an impact on the behavior of P2P individual investors, and then we want to know through what means it works, causing investors' decisions and behaviors changing? One possible approach of negative events affecting individual investors could be through the public attention. The occurrence of the vicious P2P negative events always attracts widespread public attention. In December 2015, when the management staff of Ezubao, which is a leading P2P lending platform with more than 900,000 investors and 70 billion RMB funds, suddenly absconded with all the money, it quickly became the focus of public attention and the headlines with more than 500 news reports. The high public attention has lasted for quite a few weeks. During that period, investors' search and discussion on P2P lending has also been on the rise on the Internet. Similarly, when a large number of platform negative events happened, the public always immediately paid close attention to the default risks and security issues of the whole industry. And when such attention has been formed, it will further have an impact on individual investors' subsequent investment behavior according to the limited attention theory in behavior finance [6].

In traditional finance research, scholars have proved that public attention played an important role in affecting investors' behavior, asset price, stock market activity and volatility [7]. The pattern of public attention is evolving in the digital environment [48]. With online search data, many scholars have also elaborated the boosting role of public attention on trading behaviors of individual investors in the stock market and other financial markets [3] P2P lending market is a new alternative financial market dominated by individual investors. Due to the lack of investment knowledge and experience, investors may rely more on the Internet to get information from external media especially when major negative events occur. The negative incidents and their rapid spread through the Internet often attract extensive attention of individual investors, and further arouse their worries about the money security and loans default. Exaggerations of some media coverages will also trigger panic among investors, thus affecting individual investors' behavior and decision-making in their future investment. In [16] 's research, they mentioned this amplification effect in P2P lending market. Under such theoretical foundations and realities, we propose:

H4: Negative events affect individual investors' investment behavior through public attention. 


\section{Methodology}

In this section, we describe the research methodology of the study. The process of data collection is introduced first, following with the detailed discussion of the model setting.

\subsection{Data Collection}

In order to test the above hypotheses, from CSMAR Database and WDZJ, we collect (1) all 467,594 loans transaction information on China's P2P lending platforms from October 2015 to September 2018, including daily trade volume, number of investors and the interest rate and term of each loan; (2) a total of 3,110 negative events of P2P platforms occurred from September 2015 to August 2018 in China, including platform absconding, cash withdrawal difficulties, platform closure and other negative events, as well as some basic information of these problematic platforms; (3) background information of all 6364 P2P lending platforms, including 1026 active platforms during this period. Meanwhile, in order to measure the level of public attention of P2P lending, (4) we sort out the Baidu Index of P2P lending for the same period.

Based on the main types of negative events in China's P2P lending market mentioned by [20] and their different implied risk characteristics, we divide negative events into four types:

Absconding: refers to directors or managers of P2P platforms absconding with money from investors due to poor management or with premeditation. If their purpose of operating a platform is to cheat investors and defraud funds from the very beginning, it means serious moral hazard to individual investors. Absconding is considered to be the most malignant event for individual investors, which seriously hurts investors' confidence in the P2P lending industry and has a very bad impact on the development of the entire industry.

Withdraw Difficulties: means that large amounts of investors cannot withdraw cash from the platform after the investment comes due. It does not mean that investors will certainly lose money in the future, but the occurrence of deferred payment represents an increase in the platform liquidity risk. And in reality, most platforms cannot survive such a crisis and will close down soon. The duration of P2P lending is generally shorter than traditional investments and lack of liquidity is one of the most frequently encountered problems for P2P lending platforms.

Closure: refers to P2P platforms suspending or closing its business. Generally, it will carry out liquidation and return the remaining funds to investors according to certain procedures. However, in this case, it is difficult for investors to obtain investment yields and may even face a probability of loss. To some extent, the closure of a large number of platforms also reflects the operational risks of P2P platforms due to the lack of experience of platform managers.

Others: refers to some other negative events. For example, the platform involving in the intervention of economic investigation, or the transformation of the platform business. Generally, it happens less often than the above three ones.

To ensure the consistency of the data frequency, and to better deal with the impact of negative events from a market perspective, all data are unified to monthly units. Table 1 shows the list of variables and descriptive statistics are presented in Table 2.

Table 1: Variables definition

\begin{tabular}{|l|l|l|}
\hline Variables & Unit & Definition \\
\hline TradeVolume $_{t}$ & $\begin{array}{l}10 \\
\text { thousand } \\
\text { RMB }\end{array}$ & Total investment volume of all P2P individual investors of time period $\mathrm{t}$ \\
\hline Investor $_{t}$ & $\mathrm{~N}$ & $\begin{array}{l}\text { Number of P2P individual investors participating in the investment of } \\
\text { time period } \mathrm{t}\end{array}$ \\
\hline Absconding $_{t}$ & $\mathrm{~N}$ & Number of P2P platforms absconding with money of time period $\mathrm{t}$ \\
\hline WithdrawDiff & $\mathrm{N}$ & $\begin{array}{l}\text { Number of P2P platforms having cash withdraw difficulties of time } \\
\text { period t }\end{array}$ \\
\hline Closure $_{t}$ & $\mathrm{~N}$ & Number of P2P platforms closure or suspension of time period $\mathrm{t}$ \\
\hline Others $_{t}$ & $\mathrm{~N}$ & Number of P2P platforms facing other negative events of time period $\mathrm{t}$ \\
\hline Absconding_1000 $t$ & $\mathrm{~N}$ & $\begin{array}{l}\text { Number of P2P platforms with registered capital above 10 million RMB } \\
\text { absconding with money of time period } \mathrm{t}\end{array}$ \\
\hline
\end{tabular}




\begin{tabular}{|c|c|c|}
\hline \multicolumn{3}{|l|}{ Table 1: continuation } \\
\hline WithdrawDiff_1000 $t$ & $\mathrm{~N}$ & $\begin{array}{l}\text { Number of P2P platforms with registered capital above } 10 \text { million RMB } \\
\text { having cash withdraw difficulties of time period } t\end{array}$ \\
\hline Closure_1000 $t$ & $\mathrm{~N}$ & $\begin{array}{l}\text { Number of P2P platforms with registered capital above } 10 \text { million RMB } \\
\text { closure or suspension of time period } t\end{array}$ \\
\hline Others_1000 $t$ & $\mathrm{~N}$ & $\begin{array}{l}\text { Number of P2P platforms with registered capital above } 10 \text { million RMB } \\
\text { facing other negative events of time period } t\end{array}$ \\
\hline P2PRate $_{t}$ & $\%$ & Comprehensive investment rate of $\mathrm{P} 2 \mathrm{P}$ lending of time period $\mathrm{t}$ \\
\hline P2PDuration $_{t}$ & Month & Average investment duration of $\mathrm{P} 2 \mathrm{P}$ lending of time period $\mathrm{t}$ \\
\hline $\operatorname{CSI} 300_{t}$ & $\%$ & Yield of CSI 300 index of time period $t$ \\
\hline$C P I_{t}$ & $\%$ & Sequential growth rate of Consumer Price Index of time period t \\
\hline P2PIndex $t_{t}$ & $\mathrm{~N}$ & Baidu Index of P2P lending of time period $t$ \\
\hline
\end{tabular}

Table 2: Descriptive statistics of variables

\begin{tabular}{|l|l|l|l|l|l|}
\hline Variable & Mean & Sd & Min & Max & Median \\
\hline TradeVolume & 11524907.69 & 4576174.17 & 4613821.5 & 18356830 & 11398824 \\
\hline Investor & 13688739.97 & 5952514.72 & 4544107 & 23608108 & 13194469 \\
\hline Absconding & 20.97 & 21.88 & 0 & 76 & 9 \\
\hline WithdrawDiff & 17.83 & 19.6 & 1 & 116 & 13 \\
\hline Closure & 44.61 & 32.12 & 0 & 150 & 40 \\
\hline Others & 2.97 & 2.6 & 0 & 10 & 2 \\
\hline Absconding_1000 & 18.06 & 19.49 & 0 & 61 & 6.5 \\
\hline WithdrawDiff_1000 & 15.53 & 16.69 & 1 & 99 & 11 \\
\hline Closure_1000 & 38 & 28.94 & 0 & 133 & 32.5 \\
\hline Others_1000 & 2.97 & 2.6 & 0 & 10 & 2 \\
\hline P2PRate & 0.1 & 0.01 & 0.09 & 0.13 & 0.1 \\
\hline P2PDuration & 9.09 & 1.93 & 6.68 & 14.64 & 8.81 \\
\hline CSI300 & 0 & 0.06 & -0.21 & 0.12 & 0.01 \\
\hline CPI & 0.15 & 0.5 & -1.1 & 1.6 & 0.08 \\
\hline P2PIndex & 294154.75 & 129559.86 & 146580 & 610433 & 226312 \\
\hline
\end{tabular}

As shown in Table 2, among all types of negative events of P2P lending platforms that occurred from September 2015 to August 2018, platforms closure occurred the most frequently (44.61 per month on average), followed by platforms absconding (20.97 per month on average). With considering the noise of small-scale platforms, we remove negative events happened on P2P platforms of less than 10 million RMB (25\% quantile level) registered capital, and the distribution is still similar. Also, the number of problematic platforms varies significantly from month to month, which also provides the basic conditions for our research.

As we discussed before, in China, P2P lending platforms can also be divided into several types due to their different reputation, ownership and operational modes.

In terms of ownership, private platforms (Private) are the most common and account for around $80 \%$ of all P2P platforms. In addition to private platforms, the platforms established and hold by listed companies, venture capital institutions and state-owned funds (NPrivate) are also active in the P2P lending market and are considered to operate with less moral hazard, liquidity risk and operational risk. In the form of endorsement, some platforms offer third-party guarantees for investors (Guarantee), while some other platforms not (NGuarantee). Besides, some platforms cooperate with banks or other third-party institutions to keep funds in trusteeship in order to improve the security and management of funds (Trusteeship or NTrusteeship).

Reputation is also an important indicator for platform differentiation. Platforms with good reputation can gain investors' trust, thus promoting investment. [24] showed a significant positive correlation between trust in P2P platforms and investment intentions. In addition, P2P platform with good reputation is more likely to voluntarily perform their contracts 
and strengthen investors protection to avoid vicious incidents which may undermine its reputation. We obtain the monthly reputation information of P2P lending platforms from WDZJ, and divide all active platforms into top 10 platforms (TOP10) and other platforms (NTOP10) according to the reputation ranking. Table 3 concludes the situation of P2P lending platforms of different type.

Table 3: Descriptive statistics of platform groups

\begin{tabular}{|c|c|c|c|c|c|c|}
\hline Platform Type & Variable & Mean & $\mathrm{Sd}$ & Min & Max & Median \\
\hline \multirow{2}{*}{ TOP10 } & TradeVolume & 316302.82 & 185447.06 & 59604.66 & 731659.4 & 285338.6 \\
\hline & Investor & 665983.44 & 412683.13 & 117835.34 & 1429844 & 573176.3 \\
\hline \multirow{3}{*}{ NTOP10 } & TradeVolume & 17818.12 & 5393.75 & 9055.5 & 29333.53 & 16362.13 \\
\hline & Investor & 16001 & 4947.06 & 8363.73 & 27605.6 & 15627.57 \\
\hline & Number & 474.64 & 65.68 & 290 & 534 & 499 \\
\hline \multirow{3}{*}{ Private } & TradeVolume & 18641.18 & 5975.47 & 10003.86 & 30454.42 & 18570.69 \\
\hline & Investor & 24732.23 & 10388.14 & 12617.79 & 41745.3 & 20754.55 \\
\hline & Number & 397.06 & 54.32 & 249 & 452 & 420 \\
\hline \multirow{3}{*}{ NPrivate } & TradeVolume & 44148.7 & 21783.54 & 21165.15 & 98518.8 & 38574.3 \\
\hline & Investor & 40903.61 & 16507.21 & 15947.04 & 93227.8 & 43425.76 \\
\hline & Number & 86.78 & 11.99 & 50 & 100 & 91 \\
\hline \multirow{3}{*}{ Trusteeship } & TradeVolume & 24332.08 & 7492.62 & 15278.02 & 39372.37 & 23876.93 \\
\hline & Investor & 35873.3 & 13732.9 & 19137.3 & 59202.69 & 31147.93 \\
\hline & Number & 284.17 & 43.72 & 175 & 326 & 297 \\
\hline \multirow{3}{*}{ NTrusteeship } & TradeVolume & 21999.24 & 10533.29 & 9088.58 & 46504.99 & 19736.39 \\
\hline & Investor & 16112.94 & 6479.66 & 6686.71 & 30111.68 & 16423.82 \\
\hline & Number & 199.67 & 26.85 & 124 & 249 & 206 \\
\hline \multirow{3}{*}{ Guarantee } & TradeVolume & 24669.5 & 7777.19 & 12683.52 & 37024.32 & 23200.26 \\
\hline & Investor & 30998.07 & 11276.52 & 16414.36 & 50721.87 & 30956.23 \\
\hline & Number & 406.67 & 54.54 & 260 & 456 & 426.5 \\
\hline \multirow{3}{*}{ NGuarantee } & TradeVolume & 15369.61 & 9061.66 & 2948.08 & 31305.09 & 14267.25 \\
\hline & Investor & 9676.16 & 9969.21 & 1166.36 & 31803.26 & 4461.36 \\
\hline & Number & 77.17 & 13.32 & 39 & 96 & 79.5 \\
\hline
\end{tabular}

Notes: As the number of P2P lending platforms varies greatly from month to month, the table shows the number of platforms of each type with active investment during each month. Both the trading volume and the number of investors is of the average level of active platforms of each type, in order to show the real changes of the investment in different type P2P lending platforms.

From Table 3, we can find there are significant differences in the amount of investment transactions and the number of individual investors between platforms of different types. In general, the average transaction volume and number of individual investors of platforms with higher reputation, non-private background, trusteeship and guarantee are higher than those with low reputation, private background, no trusteeship and no guarantee.

\subsection{Model Setting}

In order to verify how individual investors react to negative events in P2P lending market (Hypothesis 1), we construct a basic regression model taking the investment volume of the whole market (TradeVolume) and the number of P2P investors with new investment (Investors) of time period t as the dependent variable respectively. The independent variables are the numbers of four different kinds of negative events (Absconding, WithdrawDiff, Closure and Others) occurred in time period t-1 as we discussed above.

We select P2PRate, P2PPeriod, CSI300 and CPI as the control variables for the following reasons. First, the interest rate of P2P lending industry [35] and loans duration [25] do significantly affect individual investors' participation and trade behavior in the P2P market. Yield of CSI 300 index measures the average return in the stock market which is an important alternative market. As an indicator of investor sentiment, CSI 300 is also often used to measure the active 
level and return level of the overall financial market. Consumer Price Index (CPI), as a macro indicator, is preferred to be used to measure the inflation and the seasonal changes.

To Further ensure the model robust and alleviate heteroscedasticity, all variables in absolute value are processed in log form. The basic model is as follows:

$$
\begin{aligned}
& \text { logTradeVolume }_{t}\left(\text { logInvestor }_{t}\right)
\end{aligned}
$$

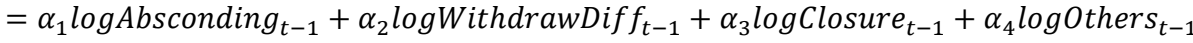

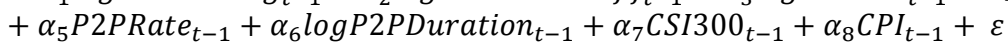

As a test of sensitivity and robustness, we eliminate negative events on P2P platforms with registered capital below RMB 10 million (25\% quantile level), in the purpose of removing the noise of negative events of very limited scale. We set up the alternative model with replacing four independent variables, Absconding, WithdrawDiff, Closure and Others, with Absconding_1000, WithdrawDiff_1000, Closure_1000 and Others_1000.

To test Hypothesis 2 and Hypothesis 3, we further extend the basic model with changing the time interval of and platform types covered in the dependent variables respectively. For Hypothesis 2, the total trading volume and individual investors number for a period of two and three months after negative events, instead of one month, are considered to test whether the feedback of individual investors in the market to platform negative events is short-lived. And for Hypothesis 3-1 to 3-4, we put average trading volume and investors number of different type P2P platforms as the dependent variables of the models respectively to see whether there are significant differences in the reactions of individual investors on different attribute platforms.

For Hypothesis 4, mediation analysis is used to test whether public attention can be the mediator through which negative events affect individual investors' trading behavior. In mediation analysis, when the influence of the independent variable on the dependent variable is affected by the influence variable, we call the variable a mediation variable. As assumed above, if the occurrence of negative events in the P2P lending market will have an impact on the level of P2P public attention, which is represented by Baidu Index of P2P (P2PIndex) here, and further affect the transaction volume in the $\mathrm{P} 2 \mathrm{P}$ market, then public attention can be the mediation variable between negative events and reaction of the individual investors. The following equations can be used to describe the relationship between variables, taking TradeVolume as the dependent variable and Absconding as an example of negative events.

$$
\begin{gathered}
\log \text { TradeVolume }=c \log \text { Absconding }+e_{1} \\
\log P 2 \text { PIndex }=\text { a logAbsconding }+e_{2} \\
\text { logTradeVolume }=c^{\prime} \log \text { Absconding }+b \log P 2 P \text { Index }+e_{3}
\end{gathered}
$$

According to[18] [18] the following steps are adopted to test the mediation effect. First, test the regression coefficient in (2). If the coefficient $c$ is significant, we proceed to the next step in which we need to check the significance of both $a$ in equation (3) and $b$ in equation (4) according to the partial mediation inspection method. Then based on complete mediation effect testing method developed by [29], we examine the coefficient $c^{\prime}$. If the coefficient $c^{\prime}$ is insignificant, it is a complete mediation process, which means the influence of the independent variable on the dependent variable is completely lying on the mediation variable; if the coefficient is significant, it can only be explained as a partial mediation process. Besides, when a or b is insignificant, a Sobel test [45] is needed to determine if the mediation effect is significant.

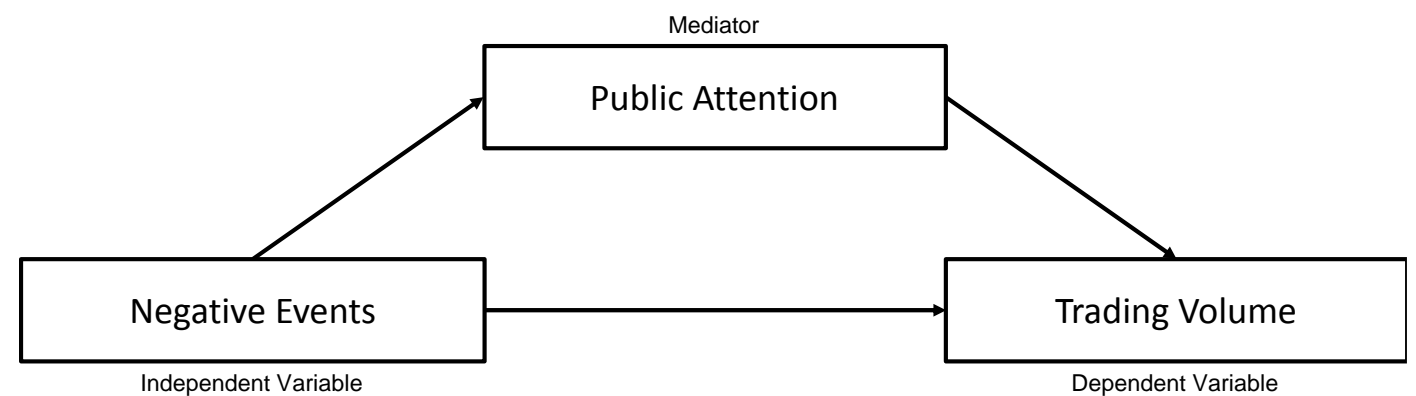

Figure 1: Public attention as the mediator

In addition to the mediation analysis, a model with cross-term is also introduced to analyze the impact mechanism of public attention as a robust test. Taking Absconding as an example of negative events, we set the cross-term model as follows: 
logTradeVolume $=\beta_{1} \log A$ bsconding $+\beta_{2} P 2$ PIndex_dummy $+\beta_{3} \log A b s c o n d i n g \times P 2 P I n d e x \_d u m m y$

$$
+\sum \text { Control Variables }+\varepsilon
$$

In order to distinguish the public attention level of the P2P index, we respectively use the median and $25 \%$ quantiles as the division line to set monthly P2P index into a dummy variable, P2PIndex_dummy, in the model. Stata 15 is used for all models processing and results output.

\section{Results}

In Table 4, the regression results of basic models are shown to verify the negative effect of negative events we proposed in Hypothesis 1. From Model (1a) and (1b), we can find that the number of platforms absconding of time period $\mathrm{t}-1$ will negatively affect the total trading volume $\left(\alpha_{1}=-0.1208, t=-2.5357\right)$ and number of investors $\left(\alpha_{1}=-0.1595\right.$, $t=-2.3809$ ) of P2P lending market of the next time period $t$ at the $5 \%$ significance level. However, the coefficients of the other three independent variables in both models are not significant, which means the withdrawal difficulties, closures and other platform negative events do not have significant influence on the subsequent trading volume and number of investors in the market.

Model (1c) and (1d) take the number of negative events happened in platform with more than RMB 10 million registered capital as instead explanatory variables to eliminate the noise of the undersized platforms and test the sensitivity. The results of coefficients show robustness and are even more significant, both trading volume $\left(\alpha_{1}=-0.1523, t=-2.9943\right)$ and number of individual investors $\left(\alpha_{1}=-0.1932, \mathrm{t}=-2.9440\right)$ show decrease after platform absconding at the significant level of $1 \%$. And for the other three dependent variables, no significant results have been found whether we exclude the impact of small-scale platforms or not.

Based on the results of basic models, we find that P2P individual investors have a quick negative feedback in terms of the trading volume and the number of investors on the absconding events. In order to further verify Hypothesis 2 , we extend the time span of dependent variables to 2 and 3 months to check whether individual investors show a similar reaction in a longer term.

From Table 5 we see that the negative reaction of individual investors on platforms absconding is rapidly decaying. Investors have a significant negative reaction to the absconding events in the following month, but the negative effects are insignificant in a longer time frame (two months and three months after the absconding events). Model (2a) and (2e) show the changes in overall trading volume in the 2- and 3-month period following platform negative events respectively, and the coefficients of all the independent variables are not significant. For the changes in the number of active investors, we find the negative effects disappear a little bit more slowly. Model (2b) shows platform absconding have a negative impact $\left(\alpha_{1}=-0.1044, \mathrm{t}=-2.0790\right)$ on the number of active investors in the next two months at a significance level of $5 \%$, while the results of Model (2f) prove that the negative effect will disappear considering next three months.

Table 4: Individual investors' reaction to negative events

\begin{tabular}{|l|l|l|l|l|}
\hline & $(1 \mathrm{a})$ & $(1 \mathrm{~b})$ & $(1 \mathrm{c})$ & $(1 \mathrm{~d})$ \\
\hline & TradeVolume $_{t}$ & Investor $_{t}$ & TradeVolume $_{t}$ & Investor $_{t}$ \\
\hline Absconding $_{t-1}$ & $-0.1208^{\star *}$ & $-0.1595^{\star *}$ & & \\
\hline & $(-2.5357)$ & $(-2.3809)$ & & \\
\hline WithdrawDiff $_{t-1}$ & -0.0430 & -0.0293 & & \\
\hline & $(-0.7165)$ & $(-0.3566)$ & & \\
\hline Closure $_{t-1}$ & 0.0440 & -0.0022 & & \\
\hline & $(1.1895)$ & $(-0.0382)$ & & \\
\hline Others $t-1$ & -0.0464 & -0.1097 & & \\
\hline & $(-0.9905)$ & $(-1.6689)$ & & \\
\hline Absconding_1000 & & & $-0.1523^{\star * *}$ & $-0.1932^{\star * *}$ \\
\hline & & & $(-2.9943)$ & $(-2.9440)$ \\
\hline WithdrawDiff_1000 $_{t-1}$ & & & -0.0057 & -0.0134 \\
\hline & & & $(-0.0972)$ & $(-0.1772)$ \\
\hline Closure_1000 $_{t-1}$ & & & 0.0506 & -0.0085 \\
\hline & & & $(1.3644)$ & $(-0.1773)$ \\
\hline
\end{tabular}




\begin{tabular}{|c|c|c|c|c|}
\hline \multicolumn{5}{|l|}{ Table 4: continuation } \\
\hline \multirow[t]{2}{*}{ Others_1000 $0_{t-1}$} & & & -0.0276 & -0.0793 \\
\hline & & & $(-0.5966)$ & $(-1.3294)$ \\
\hline \multirow[t]{2}{*}{ P2PRate $_{t-1}$} & $-16.6539^{* \star *}$ & $-13.4201^{* * *}$ & $-16.1716^{\star \star \star}$ & $-12.9396^{\star * *}$ \\
\hline & $(-8.4116)$ & $(-5.1880)$ & $(-8.0720)$ & $(-5.0073)$ \\
\hline \multirow[t]{2}{*}{ P2PDuration $_{t-1}$} & $-2.0390^{\star * *}$ & -0.7285 & $-2.2020^{\star * *}$ & -0.9534 \\
\hline & $(-4.4911)$ & $(-0.9973)$ & $(-4.9073)$ & $(-1.6472)$ \\
\hline \multirow[t]{2}{*}{$\mathrm{CSI}_{300} 00_{t-1}$} & -0.1816 & -0.0871 & -0.1784 & -0.0882 \\
\hline & $(-0.7543)$ & $(-0.3406)$ & $(-0.7602)$ & $(-0.2915)$ \\
\hline \multirow[t]{2}{*}{$\mathrm{CPI}_{t-1}$} & 0.0096 & -0.0225 & 0.0097 & -0.0182 \\
\hline & $(0.3641)$ & $(-0.5175)$ & $(0.3742)$ & $(-0.5406)$ \\
\hline \multirow[t]{2}{*}{ Constant } & $10.8979^{* * *}$ & $9.4671^{* * *}$ & $10.9717^{\star \star *}$ & $9.6336^{* * *}$ \\
\hline & $(17.1844)$ & $(9.8696)$ & $(17.7663)$ & $(12.0940)$ \\
\hline Observations & 36 & 36 & 36 & 36 \\
\hline Adjusted R-squared & 0.8575 & 0.7848 & 0.8633 & 0.8154 \\
\hline
\end{tabular}

Another interesting finding from Model $(2 \mathrm{~b})$ and $(2 \mathrm{f})$ is that, over a longer period, the number of active investors was significant negatively correlated with the number of withdrawal difficulties (For 2 months, $\alpha_{2}=-0.1257, t=-1.9930$; and for 3 months, $\alpha_{2}=-0.1343, t=-2.3341$ ). That is to say, the total number of investors involved in P2P investment has declined during a long time after the withdrawal difficulties happened. One possible explanation is that the withdrawal difficulties make the investors in the problem platforms hard to receive return and cash on time and cannot or do not willing to launch a new round of investment. It is not easy and often takes a long time for withdrawal difficulty problems to solve, so during this period, without this part of investors, the total number of P2P individual investors will drop. But overall, we can say that the negative feedback of P2P individual investors on negative events is short-lived.

Sensitivity checks have also been done by replacing independent variables with negative events only happened in platforms with registered capital above $25 \%$ quantile. The results are shown in Model (2c) - (2d) and (2g) - (2h) and all the significance comes the same.

Figure 2 and 3 further show the test results of Hypothesis 3-1 to 3-4, with changing the type of platform covered by the dependent variables and considering the different sensitivity of trading volume and individual investors in different Chinese typical types of platforms. The bar chart in Figure 2 shows the significance level of the response of average trading volume to the platform absconding events. The longer the bar is, the more significant the coefficient $\alpha_{1}$ is in the model, which means individual investors as a whole on this type of platforms are more sensitive to the negative events. Figure 3 also follows the same way, with average number of investors considered as the dependent variable instead of the average trading volume.

Table 5: Results of short-lived effect

\begin{tabular}{|c|c|c|c|c|c|c|c|c|}
\hline & \multicolumn{4}{|c|}{$t-2$} & \multicolumn{4}{|c|}{$t-3$} \\
\hline & (2a) & $(2 b)$ & (2c) & $(2 d)$ & $(2 e)$ & $(2 f)$ & $(2 \mathrm{~g})$ & $(2 \mathrm{~h})$ \\
\hline & TradeVolume & Investor $_{t}$ & TradeVolum & Investor $_{t}$ & TradeVolume & Investor $_{t}$ & TradeVolur & Investor ${ }_{t}$ \\
\hline \multirow[t]{2}{*}{ Abscongding } & -0.0693 & $-0.1044^{* *}$ & & & -0.0298 & -0.0621 & & \\
\hline & $(-1.5167)$ & $(-2.0790)$ & & & $(-0.5996)$ & $(-1.2205)$ & & \\
\hline \multirow[t]{2}{*}{ WithdrawDiff } & -0.0897 & $-0.1257^{*}$ & & & -0.0810 & $-0.1343^{* *}$ & & \\
\hline & $(-1.5642)$ & $(-1.9930)$ & & & $(-1.4420)$ & $(-2.3341)$ & & \\
\hline \multirow[t]{2}{*}{ Closure } & 0.0397 & -0.0224 & & & 0.0276 & -0.0401 & & \\
\hline & (1.1003) & $(-0.5641)$ & & & $(0.6389)$ & $(-0.9050)$ & & \\
\hline \multirow[t]{2}{*}{ Others } & -0.0137 & -0.0559 & & & 0.0173 & -0.0181 & & \\
\hline & $(-0.3029)$ & $(-1.1220)$ & & & $(0.3691)$ & $(-0.3759)$ & & \\
\hline \multirow[t]{2}{*}{ Abscongding $_{10}$} & & & $-0.0907^{*}$ & $-0.1132^{\star \star}$ & & & -0.0430 & -0.0727 \\
\hline & & & $(-1.7292)$ & $(-2.1279)$ & & & $(-0.7538)$ & $(-1.3408)$ \\
\hline \multirow[t]{2}{*}{ WithdrawDiff $f_{1}$} & & & -0.0525 & $-0.1118^{*}$ & & & -0.0498 & $-0.1177^{\star *}$ \\
\hline & & & $(-0.8924)$ & $(-1.8725)$ & & & $(-0.8639)$ & $(-2.1467)$ \\
\hline
\end{tabular}




\begin{tabular}{|c|c|c|c|c|c|c|c|c|}
\hline \multicolumn{9}{|c|}{ Table 5: continuation } \\
\hline \multirow{2}{*}{ Closure $_{1000}$} & & & 0.0519 & -0.0177 & & & 0.0334 & -0.0336 \\
\hline & & & $(1.3893)$ & $(-0.4677)$ & & & $(0.7446)$ & $(-0.7869)$ \\
\hline \multirow[t]{2}{*}{ Others $_{1000}$} & & & -0.0061 & -0.0365 & & & 0.0212 & -0.0058 \\
\hline & & & $(-0.1326)$ & $(-0.7776)$ & & & $(0.4509)$ & $(-0.1299)$ \\
\hline \multirow[t]{2}{*}{ P2PRate } & $-16.4785^{\star \star *}$ & $-12.4614^{\star \star \star}$ & $-16.2640^{\star * *}$ & $-12.3379^{\star \star \star}$ & $-16.7011^{\star \star \star}$ & $-12.6076^{\star *}$ & $-16.6760^{* \star *}$ & $-12.5927^{\star \star * *}$ \\
\hline & $(-9.0971)$ & $(-6.2552)$ & $(-8.5152)$ & $(-6.3680)$ & $(-9.3737)$ & $(-6.9018)$ & $(-8.8221)$ & $(-7.0034)$ \\
\hline \multirow[t]{2}{*}{ P2PDuration } & $-1.8363^{\star \star *}$ & -0.2476 & $-1.9724^{* * *}$ & -0.3680 & $-1.7779^{\star * *}$ & -0.0813 & $-1.8787^{\star \star *}$ & -0.2297 \\
\hline & $(-4.1953)$ & $(-0.5144)$ & $(-4.2922)$ & $(-0.7896)$ & $(-3.9425)$ & $(-0.1759)$ & $(-3.9621)$ & $(-0.5092)$ \\
\hline \multirow[t]{2}{*}{ CSI300 } & -0.2581 & -0.2070 & -0.2472 & -0.1876 & -0.1519 & -0.0347 & -0.1397 & -0.0175 \\
\hline & $(-1.1750)$ & $(-0.8569)$ & $(-1.1057)$ & $(-0.8270)$ & $(-0.6984)$ & $(-0.1554)$ & $(-0.6287)$ & $(-0.0829)$ \\
\hline \multirow[t]{2}{*}{ CPI } & 0.0259 & 0.0114 & 0.0240 & 0.0153 & 0.0309 & 0.0297 & 0.0289 & 0.0313 \\
\hline & $(1.0308)$ & $(0.4126)$ & $(0.9256)$ & $(0.5815)$ & $(1.2353)$ & $(1.1555)$ & (1.1235) & $(1.2821)$ \\
\hline \multirow[t]{2}{*}{ Constant } & $10.9708^{* \star \star}$ & $9.2567^{\star \star \star}$ & $11.0340^{\star \star *}$ & $9.3205^{\star * *}$ & $11.0648^{* \star *}$ & $9.2614^{\star \star *}$ & $11.1256^{\star * *}$ & $9.3653^{* * *}$ \\
\hline & (18.4483) & $(14.1534)$ & $(18.0770)$ & (15.0531) & $(18.6827)$ & (15.2525) & $(18.3004)$ & (16.1944) \\
\hline Observations & 35 & 35 & 35 & 35 & 34 & 34 & 34 & 34 \\
\hline $\begin{array}{l}\text { Adjusted R- } \\
\text { squared }\end{array}$ & 0.8665 & 0.8711 & 0.8602 & 0.8852 & 0.8562 & 0.8865 & 0.8489 & 0.8973 \\
\hline
\end{tabular}

In line with Hypothesis 3-1 and 3-2, individual investors' transactions on both reputable and non-private platforms are showing highly stable in terms of trading volume and investors participation with an insignificant coefficient $\alpha_{1}$. However whether the platform provides guarantees for investors' funds seems to be of tiny difference to individual investors with the coefficient $\alpha_{1}$ in all related models significantly negative. The results do not support Hypothesis 3-3. We speculate the main reason for this phenomenon may be that investors do not fully understand the qualifications of third-party guarantee agencies. Some P2P lending platforms do not disclose the guarantee information, and others may disclose with lies or colluding with guarantee institutions to cheat investors, which brings the investors insecurity. For Hypothesis $3-4$, Figure 3 shows there are significant negative changes in the number of active investors after the absconding events whether the investors are in platforms with or without trusteeship. Unexpectedly, compared with the significant negative change $\left(\alpha_{1}=-0.145, t=-3.15\right)$ in the trading volume of platforms with trusteeship, the trading volume in nontrusteeship platforms shows greater stability as in Figure 2. It is hard to explain because according to our common sense and logic, with trusteeship or not should be at least indiscriminate. Taking the reality into account, we believe that it may be related to the lack of disclosure of custody information and even the false disclosure, which resulting in the inconformity between statistical significance and practical significance. Between 2015 and 2018, China's P2P lending market was still in its early stage. The poor information disclosure and regulatory system make us unable to have an accurate understanding of the market. Another conjecture is that individual investors, especially inexperienced investors, often choose P2P lending platforms which claim trusteeship to start their investment. In fact, the average number of investors on trusteeship platforms is much higher than that on non-trusteeship platforms (35873.3 v.s. 16112.9). The increase in the number of individual investors, especially newcomers, will also increase the sensitivity of total trading volume on such platforms to negative events.

Table 6 shows the mediation effect. The results of model (4a) are consistent with the previous ones, with the trading volume in the next month showing significantly negative reaction ( $c$ in Equation (1)) to the number of absconding events. However, after we added the Baidu Index of P2P (P2PIndex) into the model (4b), the coefficient $c^{\prime}$ becomes not significant. We double checked the Sobel test which the result is -2.514 and significant at the $5 \%$ level. It illustrates that the outbreak of negative events, specifically refers to platform absconding events, can be widely spread by the Internet and attract intensive attention from the public. Further, through the public attention, it will affect investors' transactions in the P2P lending market. Thus, public attention could be the mediator between absconding events and individual investors' reaction. The results support Hypothesis 4 and the mediation effect we depicted in Figure 1.

Model (4c) and (4d) also work as a sensitivity test with only taking the number of negative events happened on platforms with registered capital above the scale as the independent variables. All the coefficients show the same sign and significance, which indicating the robustness of the model. 


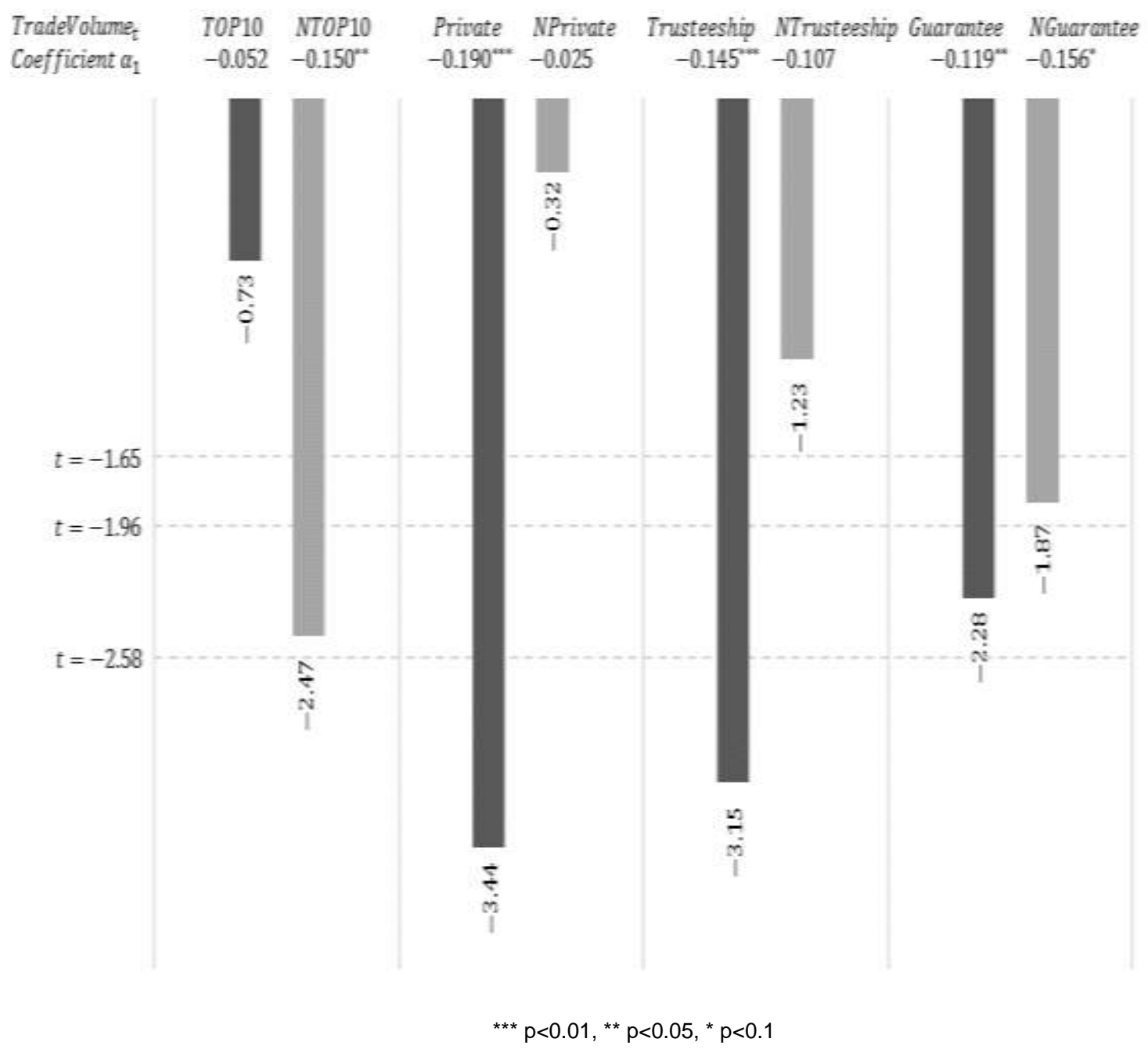

Figure 2: Effect on trading volume of different type of platforms 


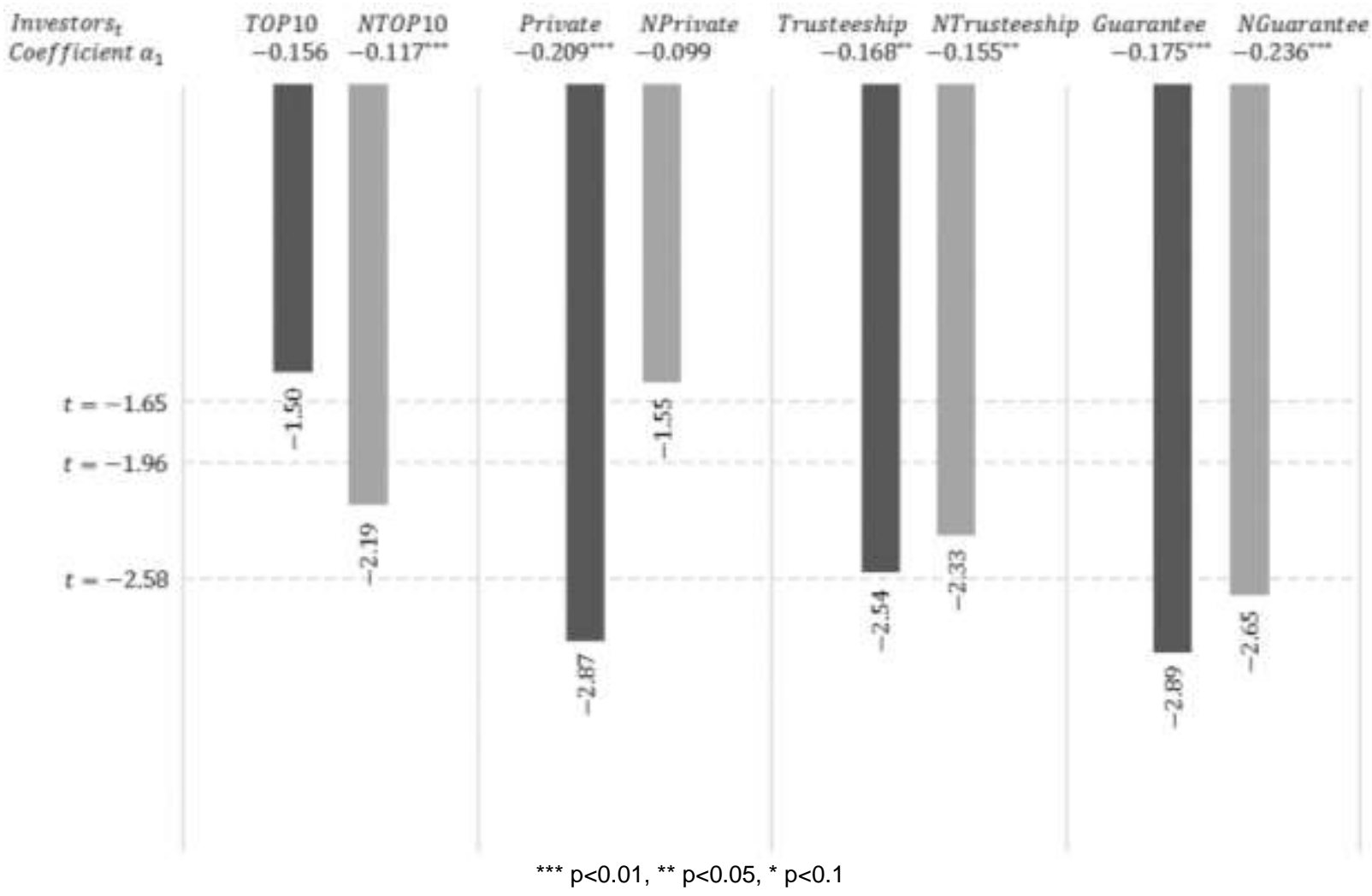

Figure 3: Effect on investors number of different type of platforms

Table 6: Mediation analysis of public attention

\begin{tabular}{|c|c|c|c|c|}
\hline & (4a) & (4b) & (4c) & (4d) \\
\hline & \multicolumn{4}{|c|}{ TradeVolume } \\
\hline \multirow[t]{2}{*}{ WithdrawDiff } & -0.0430 & -0.0729 & & \\
\hline & $(-0.7165)$ & $(-1.4191)$ & & \\
\hline \multirow[t]{2}{*}{ Closure } & 0.0440 & -0.0024 & & \\
\hline & (1.1895) & $(-0.0713)$ & & \\
\hline \multirow[t]{2}{*}{ Others } & -0.0464 & -0.0033 & & \\
\hline & $(-0.9905)$ & $(-0.0800)$ & & \\
\hline \multirow[t]{2}{*}{ WithdrawDiff $_{1000}$} & & & -0.0057 & -0.0367 \\
\hline & & & $(-0.0972)$ & $(-0.7082)$ \\
\hline \multirow[t]{2}{*}{ Closure $_{1000}$} & & & 0.0506 & 0.0081 \\
\hline & & & $(1.3644)$ & $(0.2304)$ \\
\hline \multirow[t]{2}{*}{ Others $_{1000}$} & & & -0.0276 & 0.0001 \\
\hline & & & $(-0.5966)$ & $(0.0015)$ \\
\hline \multirow[t]{2}{*}{ P2PRate } & $-16.6539^{* * *}$ & $-13.1653^{\star \star *}$ & $-16.1716^{\star * *}$ & $-13.2600^{* * *}$ \\
\hline & $(-8.4116)$ & $(-6.7442)$ & $(-8.0720)$ & $(-6.7224)$ \\
\hline \multirow[t]{2}{*}{\begin{tabular}{|l|} 
P2PPeriod \\
\end{tabular}} & $-2.0390^{* * *}$ & $-1.6345^{\star \star *}$ & $-2.2020^{* * *}$ & $-1.7918^{\star \star *}$ \\
\hline & $(-4.4911)$ & $(-4.0804)$ & $(-4.9073)$ & $(-4.3589)$ \\
\hline \multirow[t]{2}{*}{ CSI300 } & -0.1816 & -0.0854 & -0.1784 & -0.0822 \\
\hline & $(-0.7543)$ & $(-0.4165)$ & $(-0.7602)$ & $(-0.3989)$ \\
\hline \multirow[t]{2}{*}{ CPI } & 0.0096 & 0.0113 & 0.0097 & 0.0094 \\
\hline & $(0.3641)$ & (0.5061) & $(0.3742)$ & $(0.4159)$ \\
\hline
\end{tabular}




\begin{tabular}{|c|c|c|c|c|}
\hline \multicolumn{5}{|l|}{ Table 6: continuation } \\
\hline \multirow[t]{2}{*}{ Absconding } & $-0.1208^{\star *}$ & -0.0228 & & \\
\hline & $(-2.5357)$ & $(-0.4640)$ & & \\
\hline \multirow[t]{2}{*}{ Absconding $_{1000}$} & & & $-0.1523^{\star \star \star}$ & -0.0521 \\
\hline & & & $(-2.9943)$ & $(-0.9550)$ \\
\hline \multirow[t]{2}{*}{ P2PIndex } & & $-0.1877^{* * *}$ & & $-0.1713^{\star * *}$ \\
\hline & & $(-3.4537)$ & & $(-3.1318)$ \\
\hline Mediating Effect & \multicolumn{2}{|l|}{$-0.0979^{* *}$} & \multicolumn{2}{|l|}{$-0.1002^{\star \star}$} \\
\hline (Sobel Test Values) & \multicolumn{2}{|l|}{$(-2.514)$} & \multicolumn{2}{|l|}{$(-2.408)$} \\
\hline \multirow[t]{2}{*}{ Constant } & $10.8979^{* \star *}$ & $12.4609^{\star \star \star}$ & $10.9717^{\star * *}$ & $12.3877^{\star * *}$ \\
\hline & $(17.1844)$ & $(17.7813)$ & (17.7663) & $(17.6607)$ \\
\hline Observations & 36 & 36 & 36 & 36 \\
\hline Adjusted R-squared & 0.8575 & 0.8986 & 0.8633 & 0.8969 \\
\hline
\end{tabular}

t-statistics in parentheses, ${ }^{\star \star *} p<0.01,{ }^{* *} p<0.05,{ }^{*} p<0.1$.

Note: The Sobel test values are shown in the parentheses below the coefficient of mediating effect.

The cross-term models, as the robustness test of mediation analysis, are shown in Table 7. Median and $25 \%$ quantiles are respectively used as the division line to set monthly P2P index into dummy variables. In both ways, the cross-term results are negative $(-0.1716$ in Model $(4 \mathrm{e})$ and -0.2515 in Model $(4 \mathrm{~g}))$ and significant at a $5 \%$ significance level. It indicates that compared with the period of low P2P index level, the platform absconding event has a greater impact on the future trading volume when public attention of P2P is at higher level. As before, Model (4f) and (4h) serve as sensitivity tests and the results show consistent robustness.

We also use the number of individual investors as the dependent variable and it shows similar results. From the above, we further prove that the public attention is one of the most important paths via which that platforms absconding events can have an effect on the behaviors of individual investors in the P2P lending market.

Table 7: Cross-term model

\begin{tabular}{|c|c|c|c|c|}
\hline & \multicolumn{2}{|c|}{ Median Division } & \multicolumn{2}{|c|}{ 25\% Quantiles Division } \\
\hline & $(4 e)$ & (4f) & $(4 \mathrm{~g})$ & (4h) \\
\hline & \multicolumn{4}{|c|}{ TradeVolume } \\
\hline \multirow{2}{*}{ Absconding } & 0.0419 & & 0.0693 & \\
\hline & $(0.7389)$ & & $(1.0704)$ & \\
\hline \multirow[t]{2}{*}{ P2PIndex_dummy } & 0.0533 & 0.0400 & $0.1482^{* *}$ & $0.1073^{*}$ \\
\hline & $(0.6507)$ & $(0.5059)$ & $(2.5308)$ & (1.9579) \\
\hline \multirow[t]{2}{*}{ Absconding $\times$ P2PIndex_dummy } & $-0.1716^{* *}$ & & $-0.2515^{\star * *}$ & \\
\hline & $(-2.2958)$ & & $(-3.6778)$ & \\
\hline \multirow[t]{2}{*}{ WithdrawDiff } & -0.0624 & & -0.0692 & \\
\hline & $(-1.2858)$ & & $(-1.2555)$ & \\
\hline \multirow[t]{2}{*}{ Closure } & $0.0801^{* *}$ & & $0.0813^{\star \star}$ & \\
\hline & $(2.3851)$ & & $(2.5075)$ & \\
\hline \multirow[t]{2}{*}{ Others } & 0.0016 & & -0.0130 & \\
\hline & $(0.0388)$ & & $(-0.3254)$ & \\
\hline \multirow[t]{2}{*}{ Absconding $_{1000}$} & & 0.0058 & & 0.0554 \\
\hline & & $(0.0952)$ & & $(0.6463)$ \\
\hline \multirow[t]{2}{*}{ Absconding $g_{1000} \times$ P2PIndex_dummy } & & $-0.1594^{\star *}$ & & $-0.2274^{\star * \star}$ \\
\hline & & $(-2.1105)$ & & $(-2.8503)$ \\
\hline \multirow[t]{2}{*}{ WithdrawDiff $f_{1000}$} & & -0.0449 & & -0.0530 \\
\hline & & $(-0.8940)$ & & $(-0.9235)$ \\
\hline
\end{tabular}

Xueru Chen

Xiaoji Hu

Shenglin Ben 


\begin{tabular}{|c|c|c|c|c|}
\hline Closure $_{1000}$ & & $0.0772^{* *}$ & & $0.0732^{* *}$ \\
\hline & & (2.2976) & & (2.1378) \\
\hline \multirow[t]{2}{*}{ Others $_{1000}$} & & -0.0006 & & 0.0053 \\
\hline & & $(-0.0150)$ & & $(0.1238)$ \\
\hline \multirow[t]{2}{*}{ P2PRate } & $-12.4950^{* \star *}$ & $-12.5904^{* \star \star}$ & $-13.3844^{\star \star \star}$ & $-13.9077^{\star \star \star}$ \\
\hline & $(-6.3968)$ & $(-6.2931)$ & $(-7.1873)$ & $(-7.0598)$ \\
\hline \multirow[t]{2}{*}{ P2PPeriod } & $-1.5791^{* \star *}$ & $-1.7333^{* * *}$ & $-1.7461^{* * *}$ & $-1.8722^{* \star *}$ \\
\hline & $(-4.1270)$ & $(-4.3732)$ & $(-4.4787)$ & $(-4.4128)$ \\
\hline \multirow[t]{2}{*}{ CSI300 } & -0.3277 & -0.3164 & -0.3071 & -0.2772 \\
\hline & $(-1.6658)$ & $(-1.5859)$ & $(-1.5136)$ & $(-1.2903)$ \\
\hline \multirow[t]{2}{*}{$C P I$} & 0.0169 & 0.0140 & 0.0120 & 0.0128 \\
\hline & $(0.7917)$ & $(0.6408)$ & $(0.5438)$ & $(0.5423)$ \\
\hline \multirow[t]{2}{*}{ Constant } & $9.8810^{* * *}$ & $10.0644^{* * *}$ & $10.1458^{* * *}$ & $10.3253^{* * *}$ \\
\hline & (17.1446) & $(17.4010)$ & (18.0872) & $(17.2451)$ \\
\hline Observations & 36 & 36 & 36 & 36 \\
\hline Adjusted R-squared & 0.9080 & 0.9046 & 0.9024 & 0.8895 \\
\hline
\end{tabular}

\section{Further Discussion}

The above results show that the platforms absconding event is the only negative event significantly influencing individual investors' behavior in the P2P lending market. On the one hand, compared with the high moral hazard and platform subjectivity in the absconding events, the other three types of negative events seem to be not so bad. Since large amounts of P2P negative events are happening every month in China, individual investors in this market may show numbness to the regular negative events and only focus on the worst ones which have the greatest possibility to make them loss money. On the other hand, it also shows the individual investors' ignorance and lack of understanding of other kinds of risks involved in P2P platforms, including liquidity risk and operational risk which may also hurt their interests.

Different from the results of some Chinese P2P lending studies mentioned in the literature review, in this paper we find that although having a high reputation and a non-private background does reduce the sensitivity of investors on such platforms to negative events, additional credit enhancement measures such as guarantee and trusteeship have shown relatively ineffective. It may partly come from the imperfect guarantee and trusteeship mechanism of P2P lending at the present stage, the absence of regulatory and disclosure norms and investors' poor understanding of this new industry emerging in the context of FinTech.

Consistent with some of the traditional finance literature we discussed before, individual investors in this emerging market also show shortsightedness and are lack of long-term stable expectations of risks and returns. Thus, they are easily influenced by platform negative events and changing their investment decisions. When negative events occur, individual investors will always search and pay great attention to the related information on the Internet. Such attention will also make them vulnerable to the impact of public opinion orientation, especially for individual investors who lack the ability of independently thinking and judgement. It aggravates the turmoil in the whole P2P lending industry to some extent.

So, the investors education is very important. For individual investors in P2P lending market or other FinTech markets, it is critical to systematically learn and understand knowledge of finance and investment, with correctly recognizing different kind of risks. The extremely quick innovation of FinTech models and products may dazzle investors and the explosive spread of Internet information has put individual investors more vulnerable to external influences. In such cases, investors should make rational investment within the risk tolerance and protect their legitimate rights and interests.

For the government and other regulatory authorities, the innovation of regulation must keep up with the innovation of financial products and services, so that the regulation will not hinder the development of FinTech or spoil it with exposure to great risks. The regulatory authorities should make good use of RegTech and develop reasonable rules to guarantee a healthy future of the industry and protect the rights of participants. It is also important for the government to well educate individual investors and establish a good financial ethos and value orientation in the society. 


\section{Conclusion}

In this paper, with taking China's P2P lending market as an example, we try to explore the reaction of individual investors towards negative events in the context of FinTech and whether public attention plays a role in this process. Around this question, we put forward four hypotheses. By conducting regression analysis and mediation analysis with data from China's P2P lending market for a period of three years, we find that, (1) Among all four kinds of negative events (absconding, cash withdraw difficulties, closure and others) related to P2P lending platform, only platform absconding events have a significantly negative effect on the trading volume and participation of P2P individual investors in the market. The greater the number of platform absconding, the more drastically the investment volume and the number of investors will drop. (2) Individual investors have a quick reaction to the platform absconding events, but generally that negative impacts of specific negative events occurred at time period t do not show a long-term effect and are rather short-lived. (3) On different types of platforms, the individual investors also have different sensitivities for negative events. Transactions on P2P platforms with high reputation and non-private background are showing highly stable in terms of both trading volume and investors participation, while the attribute of guarantee and trusteeship has no significant influence on the stability of platform transactions. (4) Using Baidu Index, we prove that public attention can be a mediation indicator of the impact that absconding events have on individual investors. The occurrence of moral hazard such as platform absconding events, which spread rapidly through Internet and attract intensive attention from the public, directly influence behavior of individual investors in P2P lending markets. Besides, the related risk prevention, regulation and investor education issues in P2P lending market are also discussed and we make further suggestions for both the individual investors and regulators.

In the future, the behavioral research of individual investors should not be limited to the changes in market trading volume, more individual, psychological, and detailed issues need to be considered in further research. Predictably, the scale of alternative finance markets such as P2P lending and other FinTech models will continue to expand and we are going to experience a technological revolution in the financial field. The reform will constantly reshape and influence the investment philosophy, behavior and decision making of investors. Research on individual investors in these alternative finance markets will help us understand what is going on, and contribute to building a better financial world.

\section{References}

[1] G. A. Akerlof, The market for lemons: Quality uncertainty and the market mechanism, Journal of Economics, vol. 84, no. 3, pp. 489-90, 1970.

[2] H. Akerlof and S. Oncu, The stock market reaction to extreme events: The evidence from Turkey, Journal International Research Journal of Finance and Economics, vol. 6, no. 6, pp. 78-85, 2006.

[3] A. Aouadi, M. Arouri and F. Teulon, Investor attention and stock market activity: Evidence from France, Journal Economic Modelling, vol. 35, pp. 674-681, 2013.

[4] C. S. Armstrong, M. E. Barth, A. D. Jagolinzer, et al., Market reaction to the adoption of IFRS in Europe, Journal The Accounting Review, vol. 85, no. 1, pp. 31-61, 2010.

[5] E. Bajo, T. J. Chemmanur, K. Simonyan, et al., Underwriter networks, investor attention, and initial public offerings, Journal of Financial Economics, vol. 122, no. 2, pp. 376-408, 2016.

[6] H. K. Baker and J. R. Nofsinger, Behavioral Finance: Investors, Corporations, and Markets, John Wiley \& Sons, Hoboken, 2010.

[7] B. M. Barber and T. Odean, All that glitters: The effect of attention and news on the buying behavior of individual and institutional investors, The Review of Financial Studies, vol. 21, no. 2, pp. 785-818, 2007.

[8] N. Barberis and M. Huang, Mental accounting, loss aversion, and individual stock returns, The Journal of Finance, vol. 56, no. 4, pp. 1247-1292, 2001.

[9] R. Bauer, M. Cosemans and P. Eichholtz, Option trading and individual investor performance, Journal of Banking \& Finance, vol. 33, no. 4, pp. 731-746, 2009.

[10] Y. Cen, C. Zhang and C. Wu, Media information and overtrading-An empirical Study on micro-blog posts, industry news and company announcements, Data Analysis and Knowledge Discovery, vol. 2, no. 4, pp. 20-28, 2018.

[11] X. Chen, Q. Cheng and A. K. Lo, Is the decline in the information content of earnings following restatements short-lived?, Social Science Electronic Publishing, vol. 89, no. 1, pp. 177-207, 2013.

[12] A. W. K. Cheung, Do stock investors value corporate sustainability? Evidence from an event study, Journal of Business Ethics, vol. 99, no. 2, pp. 145-165, 2011.

[13] S. Chishti, How Peer to Peer Lending and Crowdfunding Drive the Fintech Revolution in the UK[M]//Banking Beyond Banks and Money. Cham: Springer, Cham, 2016, pp. 55-68.

[14] C. Y. Chung, J. Lee and J. Park, Are individual investors uninformed? Evidence from trading behaviors by heterogeneous investors around unfaithful corporate disclosure, Asia-Pacific Journal of Financial Studies, vol. 43, no. 2, pp. 157-182, 2014

[15] W. F. M. De Bondt, A portrait of the individual investor, Journal European Economic Review, vol. 42, no. 3-5, pp. 831-844, 1998.

[16] X. W. Ding, S. P. M. Gao and U. O. Illinois, Study of public opinions in typical cases in internet finance- based upon mining the internet big data of e-ZuBao, Zhong $\mathrm{J}$ in series, and other events, Editorial Friend, vol. 12, pp. 36-42, 2016. 
[17] M. A. Doan, Expanding financial communication: Investor relations, crowdfunding, and democracy in the time of fintech, M.S. thesis, The University of Waikato, Hamilton, 2018.

[18] W. N. Dudley, J. G. Benuzillo and M. S. Carrico, SPSS and SAS programming for the testing of mediation models, Nursing Research, vol. 53, no. 1, pp. 59-62, 2004.

[19] J. Engelberg and P. Gao, In search of attention, The Journal of Finance, vol. 66, no. 5, pp. 1461-1499, 2011.

[20] M. W. L. Fong, China's online peer-to-peer (P2P) lending platforms, in The Digitization of Business in China (YC. Kim and PC.Chen, Eds.). Cham: Palgrave Macmillan, 2018, pp. 43-74.

[21] S. Freedman and G. Z. Jin, Do social networks solve information problems for peer-to-peer lending? Evidence from Prosper.com, Social Science Electronic Publishing, vol. 11, p. 19, 2008

[22] S. Gervais, R. Kaniel and D. H. Mingelgrin, The high-volume return premium, The Journal of Finance, vol. 56, no. 3, pp. 877-919, 2002.

[23] X. Gong, The risk and supervision of peer-to-peer lending: Based on the assumption of bounded rationality, Review of Investment Studies, vol. 6, p. 004, 2014.

[24] M. E. Greiner and H. Wang, The role of social capital in people-to-people lending marketplaces, in Proceedings ICIS 2009, Arizona, 2009, p. 29.

[25] O. Havrylchyk and M. Verdier, The financial intermediation role of the P2P lending platforms, Comparative Economic Studies, vol. 60, no. 1, pp. 115-130, 2018.

[26] D. A. Hirshleifer, J. N. Myers, L. A. Myers, et al., Do individual investors cause post-earnings announcement drift? Direct evidence from personal trades, The Accounting Review, vol. 83, no. 6, pp. 1521-1550, 2008.

[27] J. Hu and Zhang X, The default risk and operation risk of P2P platform under the influence of shareholders' background, Journal of Shandong University, vol. 4, p. 014, 2018.

[28] C. Jing, Investor attention and macroeconomic news announcements: Evidence from stock index futures, Journal of Futures Markets, vol. 36, no. 3, pp. 240-266, 2015.

[29] C. M. Judd and D. A. Kenny, Process analysis: Estimating mediation in treatment evaluations, Evaluation Review, vol. 5, no. 5, pp. 602-619, 1981

[30] D. Kahneman, Attention and Effort. Englewood Cliffs, NJ: Prentice-Hall, 1973.

[31] R. Kaniel, S. Liu, G. Saar, et al., Individual investor trading and return patterns around earnings announcements, The Journal of Finance, vol. 67, no. 2, pp. 639-680, 2012.

[32] M. Klafft, Online peer-to-peer lending: a lenders' perspective, in Proceedings of the International Conference on E-Learning, E-Business, Enterprise Information Systems, and E-government, EEE, city, 2008, pp. 371-375.

[33] E. Lee and B. Lee, Herding behavior in online P2P lending: An empirical investigation, Electronic Commerce Research and Applications, vol. 11, no. 5, pp. 495-503, 2012.

[34] E. Lee, Equity crowdfunding in Hong Kong: potential, challenges and investor protection, Journal of Corporate Law Studies, vol. 19, no. 2, pp.277-302, 2019.

[35] Z. Li, L. Wu and H. Tang, Optimizing the borrowing limit and interest rate in P2P system: From borrowers' perspective, Scientific Programming, vol. 2018, pp. 1-14, 2018.

[36] X. Meng and Hu Y, Research on investor sentiment index based on text mining and baidu index, Macroeconomics, vol. 38, no, 1, pp. 144-153, 2016.

[37] G. M. Mian and S. Sankaraguruswamy, Investor sentiment and stock market response to earnings news, Accounting Review, vol. 87, no. 4, pp. 1357-1384, 2012.

[38] J. Miao, The Role of Investor Attention in GEM Listed Company's Stock Performance - Using Baidu Index as the Proxy of Attention, M.S. thesis, School of Management, Xiamen University, 2014.

[39] A. Moritz, J. Block and E. Lutz, Investor communication in equity-based crowdfunding: A qualitative-empirical study, Qualitative Research in Financial Markets, vol. 7, no. 3, pp. 309-342, 2015

[40] K. Parker, Method for guaranteeing a peer-to-peer loan, U.S. Patent 11/466,936, February 28, 2008.

[41] B. Qian, Effect of borrowers' reputation on borrowing cost-based on the P2P lending platform-paipai.com, Journal of Northeastern University (Social Science) vol. 17.2, pp. 141-147, 2015

[42] A. Rainer, B. Roman and M. T. Smits, FinTech and the transformation of the financial industry, Electronic Markets, vol. 28, pp. 235-243, 2018.

[43] M. S. Seasholes and G. Wu, Predictable behavior, profits, and attention, Journal of Empirical Finance, vol. 14, no. 5 , pp. 590-610, 2007

[44] R. J. Shiller, Human behavior and the efficiency of the financial system, Handbook of Macroeconomics, vol. 1, pp. 1305-1340, 1999.

[45] M. E. Sobel, Asymptotic confidence intervals for indirect effects in structural equation models, Sociological Methodology, vol. 13, pp. 290-312, 1982.

[46] H. R. Varian, Big data: New tricks for econometrics, Journal of Economic Perspectives, vol. 28, no. 2, pp. 3-28, 2014.

[47] Y. Wang and R. Hua, Guiding the healthy development of the P2P industry and promoting SME financing, in Proceedings International Conference on Management of e-Commerce and e-Government (ICMeCG). IEEE, Shanghai, 2014, pp. 318-322.

[48] J. G. Webster, The duality of media: A structurational theory of public attention, Communication Theory, vol. 21, no. 1 , pp. 43-66, 2011

[49] J. Yan, W. Yu and J. L. Zhao, How signaling and search costs affect information asymmetry in P2P lending: The economics of big data, Financial Innovation, vol. 1, no. 1, p. 19, 2015.

[50] Y. Yan, Z. Lv and B. Hu, Building investor trust in the P2P lending platform with a focus on Chinese P2P lending platforms, Electronic Commerce Research, vol. 18, no. 2, pp. 203-224, 2018. 
[51] X. Yang, L. V. Ben-Fu and M. School, Emergency, Investor Attention and Stock Market Volatility: Evidence from Web Search Data, Economic Management Journal, vol. 2, pp. 147-158, 2014.

[52] Y. H. Yeh and T. S. Lee, The interaction and volatility asymmetry of unexpected returns in the greater China stock markets, Global Finance Journal, vol. 11, no. 1-2, pp. 129-149, 2000.

[53] B. H. Yoon, J. R. Kim, Y. Y. You, et al., A study on user behaviors for consulting of fintech companies, Indian Journal of Science and Technology, vol. 9, no. 26, pp. 1-6, 2016.

[54] W. Zhang, D. Shen, Y. Zhang, et al., Open source information, investor attention, and asset pricing, Economic Modelling, vol. 33, pp. 613-619, 2013.

[55] F. Zou, Funds performance, limited attention of investors and funds subscription, Shanghai Finance, vol. 12, pp. 63-69, 2011. 